\title{
Unprecedented hydroxyl radical-dependent two-step chemiluminescence production by polyhalogenated quinoid carcinogens and $\mathrm{H}_{2} \mathrm{O}_{2}$
}

Ben-Zhan Zhu ${ }^{\mathrm{a}, \mathrm{b}, 1}$, Li Mao ${ }^{\mathrm{a}}$, Chun-Hua Huang ${ }^{\mathrm{a}}$, Hao Qin ${ }^{\mathrm{a}}$, Rui-Mei Fan ${ }^{\mathrm{a}}$, Balaraman Kalyanaramanc, and Jun-Ge Zhu ${ }^{\mathrm{a}}$

aState Key Laboratory of Environmental Chemistry and Ecotoxicology, Research Center for Eco-Environmental Sciences, Chinese Academy of Sciences, Beijing 100085, People's Republic of China; 'Linus Pauling Institute, Oregon State University, Corvallis, OR 97331; and 'Biophysics Research Institute, Medical College of Wisconsin, Milwaukee, WI 53226

Edited by Jack Halpern, The University of Chicago, Chicago, IL, and approved July 23, 2012 (received for review March 15, 2012)

\begin{abstract}
Most chemiluminescence $(\mathrm{CL})$ reactions usually generate only onestep $\mathrm{CL}$, which is rarely dependent on the highly reactive and biologically/environmentally important hydroxyl radicals $(\cdot \mathrm{OH})$. Here, we show that an unprecedented two-step $\mathrm{CL}$ can be produced by the carcinogenic tetrachloro-1,4-benzoquinone (also known as $p$ chloranil) and $\mathrm{H}_{2} \mathrm{O}_{2}$, which was found to be well-correlated to and directly dependent on its two-step metal-independent production of $\cdot \mathrm{OH}$. We proposed that $\cdot \mathrm{OH}$-dependent formation of quinonedioxetane and electronically excited carbonyl species might be responsible for this unusual two-step $\mathrm{CL}$ production by tetrachloro1,4-benzoquinone $/ \mathrm{H}_{2} \mathrm{O}_{2}$. This is a unique report of a previously undefined two-step CL-producing system that is dependent on intrinsically formed ${ }^{\circ} \mathrm{OH}$. These findings may have potential applications in detecting and quantifying ${ }^{\circ} \mathrm{OH}$ and the ubiquitous polyhalogenated aromatic carcinogens, which may have broad biological and environmental implications for future research on these types of important species.
\end{abstract}

halogenated quinones | trichlorohydroxy-1,4-benzoquinone | dichloromaleic acid | halogenated phenols | light emission

$\mathbf{P}^{\mathrm{o}}$ olyhalogenated quinones are a class of toxicological intermediates that can cause acute hepatoxicity, nephrotoxicity, and carcinogenesis $(1,2)$. They have also been observed as reactive oxidation intermediates or products in processes used to oxidize or destroy polychlorinated persistent organic pollutants in various chemical and enzymatic systems (3-7). More recently, several polyhalogenated quinones, which are suspected bladder carcinogens, were identified as new chlorination disinfection byproducts in drinking water (7). Tetrachloro-1,4-benzoquinone (TCBQ) is one of the major genotoxic and carcinogenic quinoid metabolites of the widely used wood preservative pentachlorophenol (PCP), which has been found in over one-fifth of the National Priorities List sites identified by the US Environmental Protection Agency and classified as a group 2B environmental carcinogen (3). TCBQ itself has been widely used as a fungicide for treatment of seeds, and as an oxidizing or dehydrating agent in organic synthesis (often called $p$-chloranil).

The hydroxyl radical $(\bullet \mathrm{OH})$ is an extremely reactive oxidant, important in chemistry, biology, medicine, and atmospheric and environmental science $(3,8-13)$. In biology, ${ }^{\bullet} \mathrm{OH}$ is recognized as the most reactive and harmful of the so-called reactive oxygen species (ROS), which can cause DNA, protein, and lipid oxidation (8-10). Cancer, arthritis, and Parkinson's disease are but a few of the ailments that are linked to ${ }^{\bullet} \mathrm{OH}(8)$. In environmental and atmospheric chemistry, ${ }^{\bullet} \mathrm{OH}$ is also important because of its ability to oxidize and destroy organic pollutants efficiently and has been referred to as the atmosphere's "detergent" (3-6, 11-13). One of the most widely accepted mechanisms for ${ }^{\circ} \mathrm{OH}$ production is through the transition metal-catalyzed Fenton reaction $(3,8-10)$. Recently, however, we found that ${ }^{\bullet} \mathrm{OH}$ could be produced independent of transition metal ions by hydrogen peroxide $\left(\mathrm{H}_{2} \mathrm{O}_{2}\right)$ with TCBQ and other halogenated quinones
$(14,15)$. A unique nucleophilic substitution coupled with homolytic decomposition reaction mechanism was proposed $(3,15)$. We also found that alkoxyl and carbon-centered quinone ketoxy radicals could be produced by halogenated quinone-mediated decomposition of organic hydroperoxides through a similar mechanism (16-18). Interestingly, it was recently observed by others that, in the presence of fluorescent agent riboflavin, chemiluminescence (CL) could be produced by $\mathrm{H}_{2} \mathrm{O}_{2}$ and brominated quinoid compounds isolated from acorn worm, a luminous marine organism (19). However, neither the underlying molecular mechanism for CL production nor its possible correlation with ${ }^{\bullet} \mathrm{OH}$ production is clear.

Therefore, in the present study we addressed the following questions: (i) Can CL be produced by halogenated quinones and $\mathrm{H}_{2} \mathrm{O}_{2}$ in the absence of a fluorescent agent; (ii) If so, are there any correlations between ${ }^{\circ} \mathrm{OH}$ and $\mathrm{CL}$ production; (iii) Is CL dependent on ${ }^{-} \mathrm{OH}$ production; (iv) What are the molecular mechanisms underlying $\mathrm{CL}$ and ${ }^{\circ} \mathrm{OH}$ production; and (v) What are the potential biological and environmental implications?

\section{Results and Discussion}

TCBQ and $\mathrm{H}_{2} \mathrm{O}_{2}$ Can Produce Two-Step CL, Even in the Absence of Fluorescent Agents. We found, surprisingly, that even in the absence of fluorescent agents, CL could be produced by TCBQ and $\mathrm{H}_{2} \mathrm{O}_{2}$ (Fig. $1 A$ ). In contrast, neither TCBQ nor $\mathrm{H}_{2} \mathrm{O}_{2}$ alone could produce any CL (Fig. 1A). The intensity of the CL was found to be dependent on both TCBQ and $\mathrm{H}_{2} \mathrm{O}_{2}$ : The higher the concentrations of TCBQ and $\mathrm{H}_{2} \mathrm{O}_{2}$, the stronger the CL (Fig. $1 B$ and $C$ ). The CL was also found to depend on $\mathrm{pH}$ of the buffer: No CL was observed at $\mathrm{pH} \leq 3$, but as the $\mathrm{pH}$ was increased the intensity of $\mathrm{CL}$ increased progressively, then reached maximum at $\mathrm{pH}$ 9; further increase of $\mathrm{pH}$, however, led to a decline of $\mathrm{CL}$ intensity (Fig. 1D). The approximate $\mathrm{CL}$ quantum yield for TCBQ/ $\mathrm{H}_{2} \mathrm{O}_{2}$ system was found to be about $(4.36 \pm 0.05) \times 10^{-6} E_{\mathrm{mol}}{ }^{-1}$, which was determined by using luminol as the relative standard (20). This suggests that the $\mathrm{CL}$ emission from TCBQ/ $\mathrm{H}_{2} \mathrm{O}_{2}$ system is a low-level CL.

More interestingly, an unusual two-step CL was found to be produced by TCBQ and $\mathrm{H}_{2} \mathrm{O}_{2}$ : The first one was strong but shortlived (2-6 sec) with maximum CL emission at band 490-535 nm, and the second one was weak but lasted longer $(\geq 120 \mathrm{sec})$ with maximum at band $535-555 \mathrm{~nm}$ (Fig. $1 A$ and $E$ ).

Analogous two-step CL was observed when TCBQ was substituted with other tetrahalogenated quinones, including tetrabro-

\footnotetext{
Author contributions: B.-Z.Z. and L.M. designed research; L.M., C.-H.H., H.Q., R.-M.F., and J.-G.Z. performed research; B.K. contributed new reagents/analytic tools; B.-Z.Z. and L.M. analyzed data; and B.-Z.Z. and L.M. wrote the paper.

The authors declare no conflict of interest.

This article is a PNAS Direct Submission.

${ }^{1}$ To whom correspondence should be addressed. E-mail: bzhu@rcees.ac.cn.

This article contains supporting information online at www.pnas.org/lookup/suppl/ doi:10.1073/pnas.1204479109/-/DCSupplemental.
} 

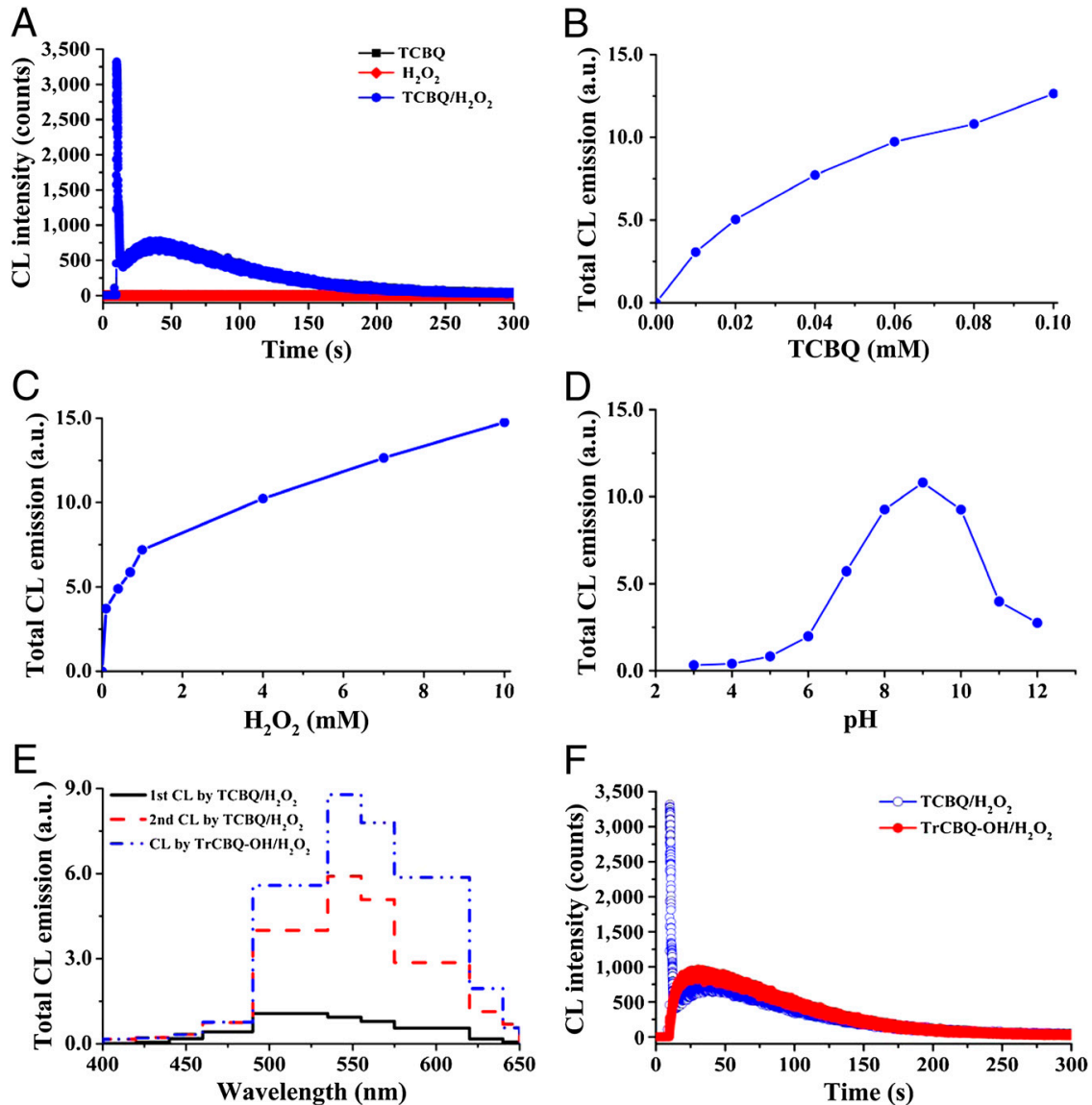

Fig. 1. TCBQ and $\mathrm{H}_{2} \mathrm{O}_{2}$ can produce two-step $\mathrm{CL}$, even in the absence of fluorescent agents. (A) Two-step $\mathrm{CL}$ could be produced by TCBQ and $\mathrm{H}_{2} \mathrm{O}_{2}$. TCBQ, $0.1 \mathrm{mM} ; \mathrm{H}_{2} \mathrm{O}_{2}, 100 \mathrm{mM}$. (B-D) The effects of TCBQ, $\mathrm{H}_{2} \mathrm{O}_{2}$, and pH on CL production by TCBQ/ $\mathrm{H}_{2} \mathrm{O}_{2}$. TCBQ, $0.2 \mathrm{mM} ; \mathrm{H}_{2} \mathrm{O}_{2}, 5 \mathrm{mM}$. (E and $\left.F\right)$ The second-step CL produced by TCBQ $/ \mathrm{H}_{2} \mathrm{O}_{2}$ is the same as the $\mathrm{CL}$ by TrCBQ-OH/ $\mathrm{H}_{2} \mathrm{O}_{2}$ : Emission spectra $(E)$ and time course $(F)$. TCBQ, $0.1 \mathrm{mM} ; \operatorname{TrCBQ}-\mathrm{OH}, 0.1 \mathrm{mM} ; \mathrm{H}_{2} \mathrm{O}_{2}, 100 \mathrm{mM}$. All reactions were carried out in Chelex-pretreated phosphate buffer (0.1 M, pH 7.4).

mo-1,4-benzoquinones and their corresponding hydroquinone forms, as well as tetrabromo- and tetrachloro-1,2-benzoquinones (Figs. S1 and S2). These findings demonstrated that the two-step $\mathrm{CL}$ production is a general phenomenon between $\mathrm{H}_{2} \mathrm{O}_{2}$ and all tetrahalogenated quinoid compounds.

The Two-Step CL Production by TCBQ $/ \mathrm{H}_{2} \mathrm{O}_{2}$ Was Found to Be Well Correlated to Its Two-Step Hydroxyl Radical Production. We showed recently that ${ }^{\bullet} \mathrm{OH}$ could be produced by TCBQ with $\mathrm{H}_{2} \mathrm{O}_{2}$ through a previously undefined mechanism of nucleophilic substitution followed by homolytical decomposition (15). Based on this mechanism, we hypothesized that the initial transient intermediate trichlorohydroxy-1,4-benzoquinone $\left(\mathrm{TrCBQ}-\mathrm{O}^{-}\right)$may further react with excess $\mathrm{H}_{2} \mathrm{O}_{2}$ to produce another molecule of ${ }^{\bullet} \mathrm{OH}$ and 2,5-dichloro-3,6-dihydroxy-1,4-benzoquinone (DDBQ, also called chloranilic acid) (3). In other words, the production of - $\mathrm{OH}$ by $\mathrm{TCBQ} / \mathrm{H}_{2} \mathrm{O}_{2}$ might be also a two-step process.

To test whether this is the case and whether there is any correlation between ${ }^{\bullet} \mathrm{OH}$ and $\mathrm{CL}$ production by $\mathrm{TCBQ} / \mathrm{H}_{2} \mathrm{O}_{2}$, the reaction between TCBQ and $\mathrm{H}_{2} \mathrm{O}_{2}$ was further studied by complementary application of various analytical methods.

The initial transient intermediate and final products between TCBQ and $\mathrm{H}_{2} \mathrm{O}_{2}$ were identified by electrospray ionization quadrupole time-of-flight mass spectrometry (ESI-Q-TOF-MS). As expected, we found that, in the presence of excess $\mathrm{H}_{2} \mathrm{O}_{2}$, TCBQ was first converted to the initial transient intermediate TrCBQ$\mathrm{OH}$, and then further to the final product DDBQ (Fig. $2 A-C$ and SI Materials and Methods). To test whether TrCBQ-OH could also be directly converted to DDBQ in the presence of $\mathrm{H}_{2} \mathrm{O}_{2}$, TrCBQ-OH was synthesized according to a published method
(15); we found that it was indeed the case (Fig. $2 D-F$ ). However, no further reaction was observed between DDBQ and $\mathrm{H}_{2} \mathrm{O}_{2}$. These results suggest that the reaction between TCBQ and $\mathrm{H}_{2} \mathrm{O}_{2}$ is a two-step process.

The time course for ${ }^{\bullet} \mathrm{OH}$ production by TCBQ/ $\mathrm{H}_{2} \mathrm{O}_{2}$ was followed by both ESR with DMPO (5,5-dimethyl-1-pyrroline- $N$ oxide) as the spin-trapping agent, and fluorescent method with coumarin-3-carboxylic acid (3-CCA) as an ${ }^{\bullet} \mathrm{OH}$ probe. Two clearcut phases of ${ }^{\bullet} \mathrm{OH}$ production were observed: The first phase is fast, whereas the second is much slower (Fig. $3 A$ and $B$ ). This demonstrated that two-step ${ }^{\bullet} \mathrm{OH}$ could be produced by two-step reactions between TCBQ and $\mathrm{H}_{2} \mathrm{O}_{2}$.

The above results suggested that each step of reaction between TCBQ and $\mathrm{H}_{2} \mathrm{O}_{2}$ might produce ${ }^{\bullet} \mathrm{OH}$ and CL, and the secondstep $\bullet \mathrm{OH}$ formation and $\mathrm{CL}$ emission should be produced by the reaction of $\mathrm{H}_{2} \mathrm{O}_{2}$ with $\mathrm{TrCBQ}-\mathrm{OH}$, the transient intermediate produced during the first-step reaction between TCBQ and $\mathrm{H}_{2} \mathrm{O}_{2}$. We found that this was exactly the case: The time course and the emission spectrum of the second-step CL produced by TCBQ and $\mathrm{H}_{2} \mathrm{O}_{2}$ were almost the same as compared with that produced by $\mathrm{TrCBQ}-\mathrm{OH}$ and $\mathrm{H}_{2} \mathrm{O}_{2}$ (Fig. $1 F$ ), and $\bullet \mathrm{OH}$ could also be produced by $\operatorname{TrCBQ}-\mathrm{OH}$ and $\mathrm{H}_{2} \mathrm{O}_{2}$, which is much weaker and slower as compared with the first-step ${ }^{\bullet} \mathrm{OH}$ production by TCBQ $/ \mathrm{H}_{2} \mathrm{O}_{2}$ (Fig. 3C). Similar pH-dependent effects were also observed for both ${ }^{\circ} \mathrm{OH}$ and $\mathrm{CL}$ production by $\mathrm{TCBQ} / \mathrm{H}_{2} \mathrm{O}_{2}$ (Fig. 3D).

Taken together, the above findings showed that the production of $\bullet \mathrm{OH}$ by TCBQ/ $\mathrm{H}_{2} \mathrm{O}_{2}$ is a two-step process, and the two-step - $\mathrm{OH}$ production was correlated well with the two-step CL 

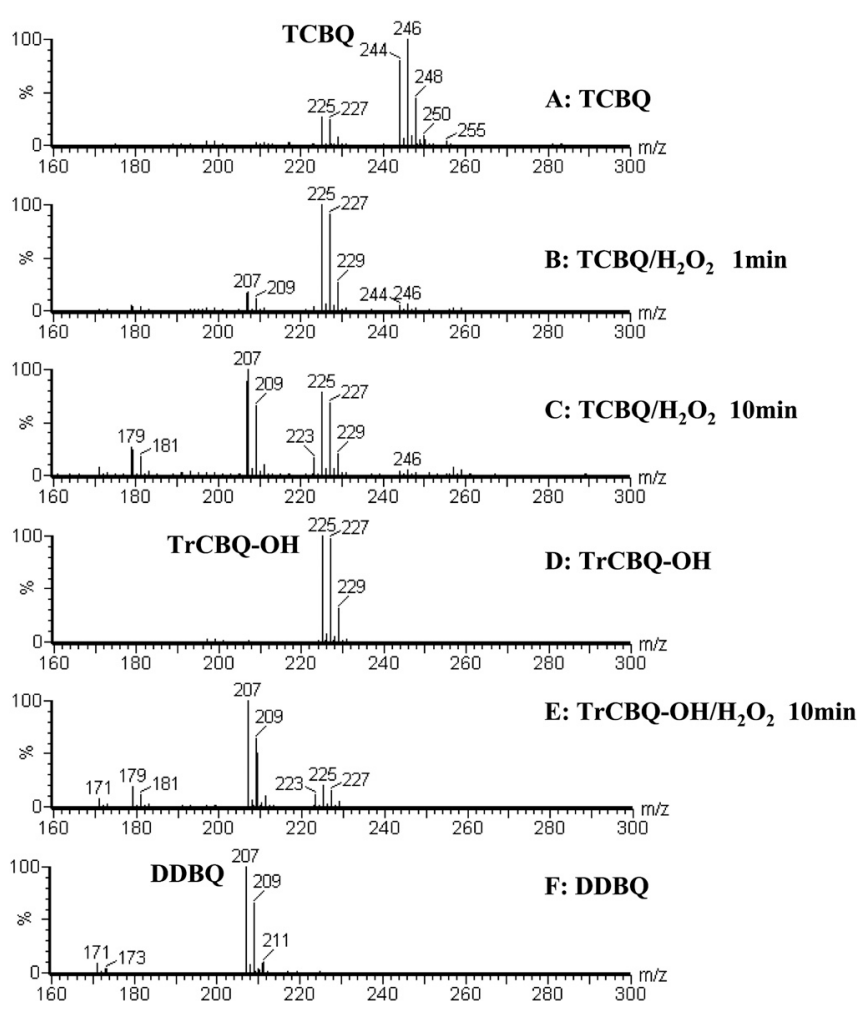

Fig. 2. Identification of reaction intermediate and product for TCBQ and $\mathrm{H}_{2} \mathrm{O}_{2}$ by ESI-Q-TOF-MS. (A) ESI-negative-Q-TOF-MS spectra of TCBQ; $(B)$ $\mathrm{TCBQ} / \mathrm{H}_{2} \mathrm{O}_{2}, 1 \mathrm{~min}$; $(C) \mathrm{TCBQ} / \mathrm{H}_{2} \mathrm{O}_{2}, 10 \mathrm{~min}$; $(D) \mathrm{TrCBQ}-\mathrm{OH}$; $(E) \mathrm{TrCBQ}-\mathrm{OH} /$ $\mathrm{H}_{2} \mathrm{O}_{2}, 10 \mathrm{~min}$; $(F)$ DDBQ. TCBQ, $0.5 \mathrm{mM}$; TrCBQ-OH, $0.5 \mathrm{mM}$; DDBQ, $0.5 \mathrm{mM}$; $\mathrm{H}_{2} \mathrm{O}_{2}, 100 \mathrm{mM}$. All reactions were carried out in Chelex-pretreated ammonia acetate buffer $(0.1 \mathrm{M}, \mathrm{pH} 7.4)$.

production by TCBQ $/ \mathrm{H}_{2} \mathrm{O}_{2}$. These results indicate that ${ }^{\bullet} \mathrm{OH}$ might be involved in the two-step CL production.

The $\mathrm{CL}$ Production by TCBQ/ $\mathrm{H}_{2} \mathrm{O}_{2}$ Was Directly Dependent on $\cdot \mathbf{O H}$ Formation. We found that the two-step CL production by TCBQ $/ \mathrm{H}_{2} \mathrm{O}_{2}$ was indeed directly dependent on ${ }^{\bullet} \mathrm{OH}$ formation. This was based on the following lines of evidence: $(i)$ The $\mathrm{CL}$ produced by TCBQ/ $\mathrm{H}_{2} \mathrm{O}_{2}$ was markedly inhibited by several well-known ${ }^{\bullet} \mathrm{OH}$ scavengers, such as DMSO, formate, and ethanol (Fig. $3 E$ ), and the concentrations for each ${ }^{\bullet} \mathrm{OH}$ scavenger to inhibit $50 \%$ of $\mathrm{CL}\left(\mathrm{IC}_{50}\right)$ were found to be $9.3,8.5$, and $45 \mathrm{mM}$, respectively, which are inversely correlated with their rate constants with $\bullet \mathrm{OH}$ (8) (Fig. 3E); (ii) CL production by TCBQ $/ \mathrm{H}_{2} \mathrm{O}_{2}$ could be further enhanced significantly (up to four times) by extra ${ }^{\bullet} \mathrm{OH}$ produced by addition of the iron complex $\mathrm{Fe}$ (II)-EDTA, a classic Fenton reagent that can react with $\mathrm{H}_{2} \mathrm{O}_{2}$ to produce $\bullet \mathrm{OH}$ (Fig. $3 F$ ); (iii) CL could be produced by TCBQ only with $\mathrm{H}_{2} \mathrm{O}_{2}$, but not with organic hydroperoxides such as tert-butyl hydroperoxide $(t-\mathrm{BuOOH})$ and cumene hydroperoxide $(\mathrm{CuOOH})$ under the same experimental conditions (Fig. S3), which is consistent with the fact that ${ }^{\bullet} \mathrm{OH}$ could be produced by TCBQ only with $\mathrm{H}_{2} \mathrm{O}_{2}$, but not with organic hydroperoxides (only alkoxyl radicals were produced in these cases); and (iv) CL could be produced by $\mathrm{H}_{2} \mathrm{O}_{2}$ not only with TCBQ, but also with all other halogenated quinones, but not with non- or methyl-substituted quinones (Fig. S4). This is also in agreement with our previous finding that ${ }^{\bullet} \mathrm{OH}$ could be produced only by halogenated quinones, but not with non- or methyl-substituted quinones (see ref. 14). To our knowledge, this is a unique report showing that the CL production is well-correlated and directly dependent on $\cdot \mathrm{OH}$ formation.
The above findings may have some potential applications. For example, the method could be used as a rapid and specific chemiluminescent method for detecting and measuring metal-independent $\cdot \mathrm{OH}$ production by halogenated quinones and $\mathrm{H}_{2} \mathrm{O}_{2}$; estimating the rate constant with ${ }^{\bullet} \mathrm{OH}$ of an unknown compound; and evaluating the ${ }^{\bullet} \mathrm{OH}$-scavenging abilities of various antioxidants, food extracts, and herbal preparations. The unique advantage of this method is that the source of $\bullet \mathrm{OH}$ can be produced independent of transition metal ions by halogenated quinones and $\mathrm{H}_{2} \mathrm{O}_{2}$.

The Major Ring-Opening Products Between TCBQ and $\mathrm{H}_{2} \mathrm{O}_{2}$ Were Identified as 2,3-Dichloromaleic Acid and $\mathbf{C O}_{2}$. As shown above, the two hydroxylated quinones TrCBQ-OH and DDBQ were identified as transient and final product between TCBQ and $\mathrm{H}_{2} \mathrm{O}_{2}$. To our surprise, the quantitative analysis by HPLC showed that the yield of the final product DDBQ after TCBQ reaction with excessive $\mathrm{H}_{2} \mathrm{O}_{2}$ was only $9.8 \%$ (Table $\mathrm{S} 1$ ). This indicates that other products (other than DDBQ) should be formed, too. However, no other products could be readily identified by MS or HPLC using previously published methods $(15,18)$. To solve this problem, qualitative and quantitative analysis of all reaction products from TCBQ $/ \mathrm{H}_{2} \mathrm{O}_{2}$ were conducted systematically by complementary applications of multiple analytical methods: GC-MS, Q-TOF-MS-HPLC, and ion chromatography (IC). We found that, unexpectedly, beside DDBQ, three quinone ring-opening products were also formed. The major ring-opening product was identified as dichloromaleic acid (DCMA), and the other two minor ring-opening products were chloromalonic acid (CMA) and oxalic acid (Figs. S5 and S6). The IC quantitative results showed that the yields of DCMA, CMA, and oxalic acid from TCBQ $/ \mathrm{H}_{2} \mathrm{O}_{2}$ were $32.3 \%, 13.4 \%$, and $12.2 \%$, respectively (Table S1). The remaining $32.3 \%$ TCBQ was found to be converted to $\mathrm{CO}_{2}$ (and/or $\mathrm{CO}$ ) through total organic carbon (TOC) analysis.

DDBQ, CMA, oxalic acid, and $\mathrm{CO}_{2}$ (and/or $\mathrm{CO}$ ), but not DCMA, were identified as the final products for the reaction between TrCBQ-OH and $\mathrm{H}_{2} \mathrm{O}_{2}$, and their yields were $33.1 \%$, $17.8 \%, 21.3 \%$, and $27.8 \%$, respectively (Fig. S6 and Table S1).

In summary, the product analysis showed that $\mathrm{H}_{2} \mathrm{O}_{2}$ not only causes the dechlorination and hydroxylation of TCBQ to form TrCBQ-OH and DDBQ, but also causes quinone ring-opening to form DCMA, CMA, oxalic acid, and $\mathrm{CO}_{2}$ (and/or CO). To our knowledge, this is also a previously uncharacterized report showing TCBQ could decompose to form small-molecule organic acids by $\mathrm{H}_{2} \mathrm{O}_{2}$. It has been suggested that $\mathrm{H}_{2} \mathrm{O}_{2}$-dependent decomposition pathway for halogenated quinones may be important in systems where $\mathrm{H}_{2} \mathrm{O}_{2}$ is either used or produced. However, the exact molecular mechanisms underlying such further transformations are not clear. Our findings may provide a unique perspective to understand better such transformation mechanisms during wastewater treatment or remediation processes in which halogenated quinones are formed.

Possible Light-Emitting Intermediates. Chemiluminescence is a phenomenon in which chemically generated molecules in excited states liberate energy with light emission, which is generally accompanied by decomposition of organic peroxides (21-26). Based on the luminescent properties of electronically excited product, CL could be divided as direct CL, in which excited product directly exhibits CL, and indirect CL, such as chemically initiated electron-exchange luminescence (CIEEL), in which excited product first transfers the excitation energy to suitable luminescer, and then the electronically excited luminescer emits CL (21-23). If the CL production by TCBQ/ $\mathrm{H}_{2} \mathrm{O}_{2}$ were through the CIEEL mechanism, the addition of fluorescent agents such as riboflavin or 9,10-diphenylanthracene (DPA) should have marked impact on CL production (21-23). However, no such effect was 

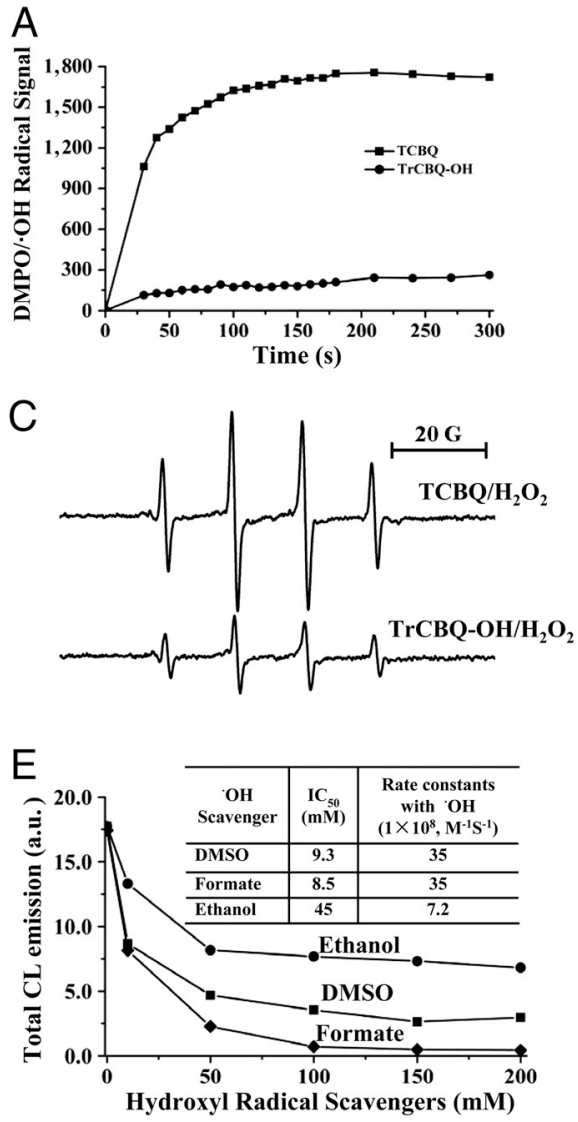

B
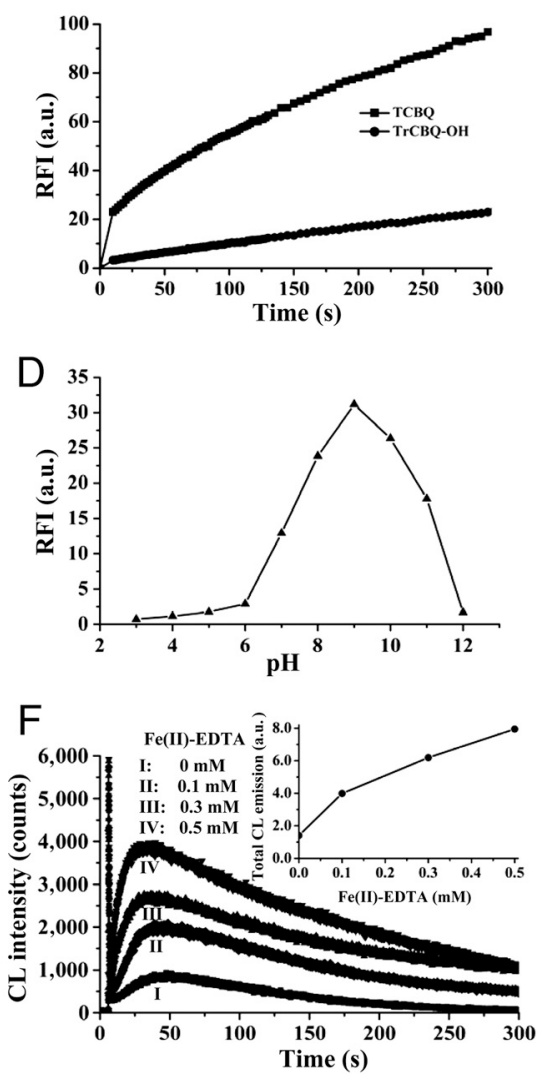

Fig. 3. The two-step $\mathrm{CL}$ production by $\mathrm{TCBQ} / \mathrm{H}_{2} \mathrm{O}_{2}$ was well-correlated to and directly dependent on its two-step hydroxyl radical production. ( $A$ and $B$ ) The ESR and fluorescent kinetic study on ${ }^{\circ} \mathrm{OH}$ production by TCBQ/ $\mathrm{H}_{2} \mathrm{O}_{2}$. TCBQ, $0.1 \mathrm{mM} ; \mathrm{TrCBQ}-\mathrm{OH}, 0.1 \mathrm{mM} ; \mathrm{H}_{2} \mathrm{O}_{2}, 1 \mathrm{mM} ; \mathrm{DMPO}, 100 \mathrm{mM} ; 3-\mathrm{CCA}, 4 \mathrm{mM}$. (C) ESR detection of ${ }^{\circ} \mathrm{OH}$ production by TCBQ/ $\mathrm{H}_{2} \mathrm{O}_{2}$ and TrCBQ-OH/ $\mathrm{H}_{2} \mathrm{O}_{2}$. TCBQ, $0.5 \mathrm{mM}$; TrCBQ-OH, $0.5 \mathrm{mM} ; \mathrm{H}_{2} \mathrm{O}_{2}, 5 \mathrm{mM}$; DMPO, $100 \mathrm{mM}$. (D) The pH-dependent - $\mathrm{OH}$ production by TCBQ/ $\mathrm{H}_{2} \mathrm{O}_{2}$ by fluorescent method. TCBQ, $0.1 \mathrm{mM} ; \mathrm{H}_{2} \mathrm{O}_{2}, 1 \mathrm{mM} ; 3-\mathrm{CCA}, 1 \mathrm{mM}$. (E) The $\mathrm{CL}$ production by TCBQ/ $\mathrm{H}_{2} \mathrm{O}_{2}$ was quenched by the classic ${ }^{\circ} \mathrm{OH}$ scavengers. TCBQ, $0.1 \mathrm{mM} ; \mathrm{H}_{2} \mathrm{O}_{2}, 100 \mathrm{mM}$. $(F) \mathrm{CL}$ production by TCBQ $/ \mathrm{H}_{2} \mathrm{O}_{2}$ was further enhanced by addition of Fe(II)-EDTA. TCBQ, $0.1 \mathrm{mM} ; \mathrm{H}_{2} \mathrm{O}_{2}$, $100 \mathrm{mM}$. All reactions were carried out in Chelex-pretreated phosphate buffer (0.1 M, pH 7.4).

observed. These results indicate that CIEEL mechanism may not be responsible for the CL production by TCBQ/ $\mathrm{H}_{2} \mathrm{O}_{2}$; in other words, the CL produced by TCBQ/ $\mathrm{H}_{2} \mathrm{O}_{2}$ must be a direct or intrinsic one: Some light-emitting intermediates must be generated during the reaction of TCBQ with $\mathrm{H}_{2} \mathrm{O}_{2}$. The fact that several ring-opening products were formed during TCBQ $/ \mathrm{H}_{2} \mathrm{O}_{2}$ reaction also suggests that the process of quinone ring opening might be responsible for generating excited light-emitting species and the corresponding energy required for CL emission.

A class of high-energy four membered-ring peroxides, 1,2dioxetanes, has been proposed as the critical intermediate in many chemiluminescent reactions (21-24); 1,2-dioxetanes have received a great deal of attention because of their unique ability to decompose thermally into electronically excited carbonyl products. We propose that an unusual quinone 1,2-dioxetane intermediate might be produced during the reaction between TCBQ and $\mathrm{H}_{2} \mathrm{O}_{2}$. The following thermal decomposition of quinone 1,2dioxetane might generate electronically excited carbonyl-containing compound as light emitter, which emits CL directly. If the above hypothesis were correct, the energy released during the decomposition of quinone 1,2-dioxetane should meet the energy requirement for light-emitter transiting from ground state to excited state. As anticipated, our preliminary thermochemical calculations supported the above hypothesis-the energy released from the decomposition of the proposed quinone 1,2dioxetane could reach up to $80.2 \mathrm{kcal} / \mathrm{mol}(1 \mathrm{kcal}=4.18 \mathrm{~kJ})$, which is sufficient to meet the demand of $\mathrm{CL}$ emission of $\mathrm{TCBQ} / \mathrm{H}_{2} \mathrm{O}_{2}$.
To differentiate between singlet- and triplet-excited carbonyl species as the potential light-emitting intermediates, two energy acceptors (DPA and 9,10-dibromoanthracene sulfonate) and three different dyes (fluoresin, eosin, and rose bengal) were used. We found that the CL spectra were not changed by these energy acceptors and dyes, and the CL intensity was not enhanced, but rather inhibited, at high concentrations of them. These results suggest that singlet and triplet species could not be readily differentiated by this approach. Further investigations on this issue are needed for our future studies.

Molecular Mechanism of -OH-Dependent Two-Step CL Production by TCBQ and $\mathbf{H}_{2} \mathbf{O}_{2}$. On the basis of all the above results and our previous findings $(3,14-18)$, a unique molecular mechanism was proposed for ${ }^{\circ} \mathrm{OH}$-dependent two-step CL production by TCBQ $/ \mathrm{H}_{2} \mathrm{O}_{2}$ (Scheme 1): A nucleophilic reaction may take place between TCBQ and $\mathrm{H}_{2} \mathrm{O}_{2}$, forming a quinone-hydroperoxide reaction intermediate $\mathrm{TrCBQ}-\mathrm{OOH}$, which could decompose homolytically to produce ${ }^{\bullet} \mathrm{OH}$ and the oxygen-centered enoxy radical TrCBQ-O ${ }^{\bullet}$. TrCBQ-O ${ }^{\bullet}$ then could either disproportionate to form the initial transient intermediate TrCBQ-OH or isomerize to form the carbon-centered ketoxy radical - $\operatorname{TrCBQ}=\mathrm{O}$, which could be attacked by ${ }^{\bullet} \mathrm{OH}$ to form multicarbonyl compound I. The unstable multicarbonyl compound I may further react with $\mathrm{H}_{2} \mathrm{O}_{2}$ to form a quinone 1,2-dioxetane, which would further decompose to form the ring-opening excited light emitter $[\mathrm{A}]^{*}$. The first $\mathrm{CL}$ was emitted concurrently when electronically excited state of $[\mathrm{A}]^{*}$ returned to ground state of $[\mathrm{A}]$; 


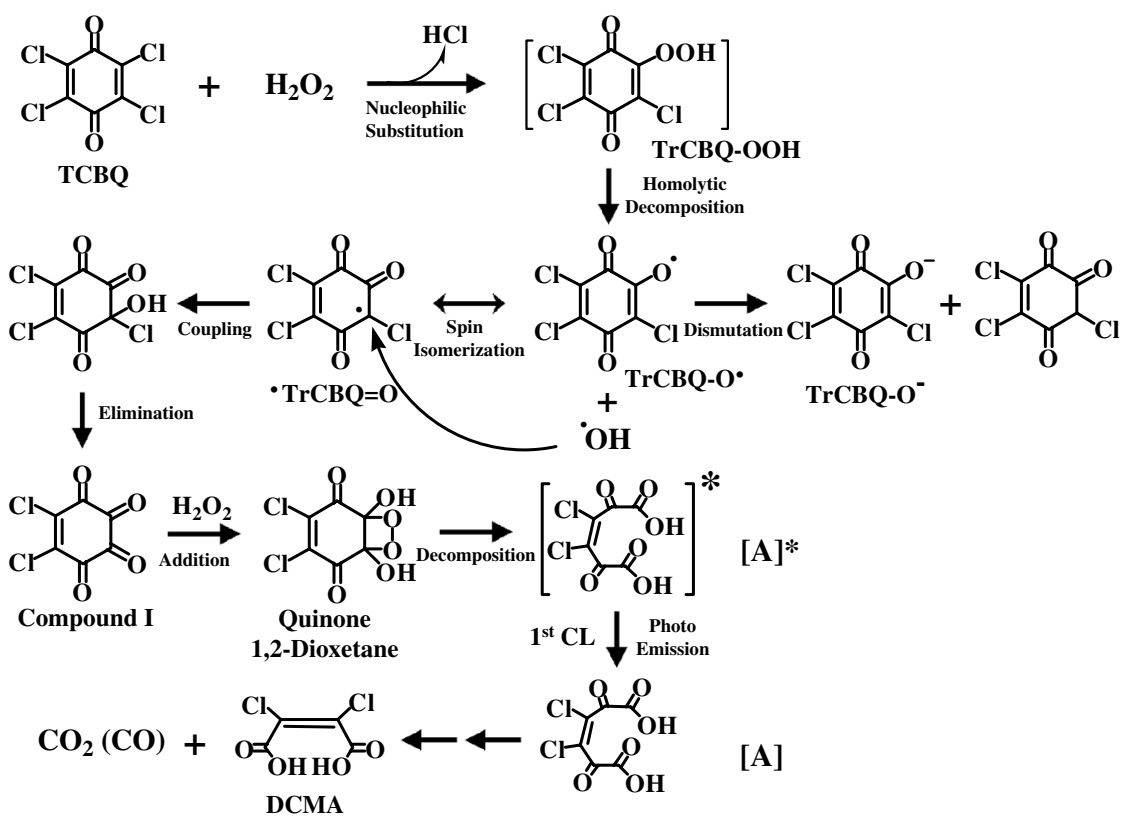

Scheme 1. Proposed molecular mechanism for the first-step $\bullet \mathrm{OH}$-dependent $\mathrm{CL}$ production by $\mathrm{TCBQ}$ and $\mathrm{H}_{2} \mathrm{O}_{2}$.

the subsequent decomposition of [A] leads to the formation of final products DCMA and $\mathrm{CO}_{2}$ (and/or $\mathrm{CO}$ ).

The second-step CL could be produced by the transient intermediate TrCBQ-OH with excessive $\mathrm{H}_{2} \mathrm{O}_{2}$ through similar pathways, during which DDBQ and other ring-opening products (CMA, oxalic acid, $\mathrm{CO}_{2}$ and/or $\mathrm{CO}$ ) would be formed (Scheme S1). However, the second CL exhibits the maximum emission at band $535-555 \mathrm{~nm}$ as compared to band $490-535 \mathrm{~nm}$ for the first CL. This might be because the light emitter $[\mathrm{B}]^{*}$ has an electron-donating hydroxyl group, which caused the second $\mathrm{CL}$ to be red shifted to longer wavelength.

To our knowledge, this is a unique report that two-step CL could be produced by tetrahalogenated quinones with $\mathrm{H}_{2} \mathrm{O}_{2}$ and that the CL production is directly and specifically dependent on two-step $\bullet \mathrm{OH}$ formation. These findings, together with the identification and quantitative analysis of the transient and final products (especially the new ring-opening products), have further confirmed and expanded our previously proposed molecular mechanism for metal-independent production of ${ }^{\circ} \mathrm{OH}$ by TCBQ $/ \mathrm{H}_{2} \mathrm{O}_{2}$.

Why This CL-Producing System Is Unique. Compared with the previously reported classic CL-producing systems (21-26), the TCBQ $/ \mathrm{H}_{2} \mathrm{O}_{2}$ CL-producing system in this study showed the following unique characteristics: The two-step CL produced by TCBQ $/ \mathrm{H}_{2} \mathrm{O}_{2}$ was directly and specifically dependent on the two-step intrinsic production of $\bullet \mathrm{OH}$, but not on other reactive oxygen species such as superoxide anion radical and singlet oxygen. It should also be noted that the $\mathrm{CL}$ produced by TCBQ $/ \mathrm{H}_{2} \mathrm{O}_{2}$ could be observed under normal physiological $\mathrm{pH}$, or even under weak acidic conditions, whereas alkaline or strong alkaline conditions are required for the classic luminol and lucigen systems. Also, no fluorescent agents are needed for CL production by TCBQ $/ \mathrm{H}_{2} \mathrm{O}_{2}$, whereas fluorescent agents are frequently required for some classic CL-producing systems (such as peroxalates).

Potential Biological and Environmental Implications. We found that when TCBQ was substituted with other polyhalogenated quinones, analogous ${ }^{\circ} \mathrm{OH}$-dependent $\mathrm{CL}$ could also be observed (Figs. S2 and S4). Therefore, our findings may have interesting biological and environmental implications: Many widely used polyhalogenated aromatic compounds, which are considered persistent organic pollutants and probable human carcinogens-including polyhalogenated phenols (such as the ubiquitous wood preservative PCP and the brominated flame-retardant 3,3',5,5'tetrabromobisphenol A), Agent Orange, hexachlorobenzene, and polychlorinated biphenyls - can be metabolized in vivo (1-3, 27-29) or dehalogenated chemically and enzymatically (4-6) to their corresponding quinones. Recently, polychlorinated quinoid compounds were also identified as new chlorination disinfection byproducts in drinking water (7) and found in discharges from pulp and paper mills (3). These polyhalogenated quinones not only cause oxidative damage to DNA and other macromolecules, but also form protein and DNA adducts both in vitro and in vivo (1-7, 27-29), and therefore are potentially carcinogenic toward mammalian organisms. Therefore, it is important to detect and measure these halogenated quinones and/or their parent compounds both in the environment and in biological systems. It is well-known that CL-based methods are inherently sensitive because of the relative ease with which low light emission can be quantified by photon-counting techniques. The fact that CL could be produced by halogenated quinones $/ \mathrm{H}_{2} \mathrm{O}_{2}$ may imply that we can use this unique CL-producing property to detect and measure halogenated quinones. Indeed, we found that as little as $10 \mathrm{nM}$ TCBQ could be quantitatively detected by this new CL method, and the linear range for TCBQ is 0.01 to approximately $100 \mu \mathrm{M}$ (SI Materials and Methods and Table S2).

Recently, $\mathrm{H}_{2} \mathrm{O}_{2}$ has been increasingly favored in the advanced oxidation processes (AOPs) as an environmentally safe oxidant for remediation of environmental pollutants, such as chlorinated phenols $(3-6,30,31)$. In these "environmentally green" systems, $\mathrm{H}_{2} \mathrm{O}_{2}$ is often used at high concentrations. The most reactive radical intermediate formed during AOPs is ${ }^{\bullet} \mathrm{OH}$ (29). Several previous studies showed that PCP could be oxidized and degraded by $\mathrm{H}_{2} \mathrm{O}_{2}$ in the presence of certain catalysts through the formation of tetrachloroquinoid intermediates $(3-6,31)$. This suggests that CL could also be produced during PCP degradation by AOPs such as the classic Fenton system, $\mathrm{Fe}(\mathrm{II})-\mathrm{EDTA} / \mathrm{H}_{2} \mathrm{O}_{2}$. We found that this is indeed the case. We took advantage of this finding and employed this highly sensitive CL method to measure quantitatively trace amounts of halogenated phenols such as PCP, 
triclosan, and 3,3',5,5'-tetrabromobisphenol A (SI Materials and Methods, Fig. S7, and Table S3). We found that the detection limit of $\mathrm{PCP}$ in the $\mathrm{PCP} / \mathrm{Fe}(\mathrm{II})-\mathrm{EDTA} / \mathrm{H}_{2} \mathrm{O}_{2}$ system is as low as 2.6 parts per billion (ppb), and the linear range for PCP is 8 to approximately 8,000 ppb. This is lower than the PCP concentration level of $40 \mathrm{ppb}$ found in the body fluids of people who are not occupationally exposed to PCP, and much lower than the level of $19,580 \mathrm{ppb}$ in occupationally exposed individuals (3). Because of the low PCP detection limit, this CL method might be used to measure PCP both in our environment and in biological systems.

\section{Materials and Methods}

CL Analysis. The $\mathrm{CL}$ produced by halogenated quinones and $\mathrm{H}_{2} \mathrm{O}_{2}$ was measured by an ultraweak CL analyzer (Institute of Biophysics, Chinese Academy of Science) with a CR-120 red-sensitive photomultiplier tube (operated at the range of -900 to approximately $-1,100 \mathrm{~V}$; Hamamatsu); the $\mathrm{CL}$ analyzer was operated in pulse mode. The $\mathrm{CL}$ determination was carried out in a 3-mL glass cuvette and started by the injection of halogenated quinones. The $\mathrm{CL}$ signal was recorded by a computer equipped with a data-acquisition interface. Data acquisition and treatment were performed with BPCL software. The total intensity of $\mathrm{CL}$ was integrated during the whole process for $\mathrm{CL}$ measurements. The $\mathrm{CL}$ emission spectra were obtained using a set of interference filters with wavelengths from 400 to $640 \mathrm{~nm}$, which were placed between the sample

1. Bolton JL, Trush MA, Penning TM, Dryhurst G, Monks TJ (2000) Role of quinones in toxicology. Chem Res Toxicol 13:135-160.

2. Song Y, Wagner BA, Witmer JR, Lehmler HJ, Buettner GR (2009) Nonenzymatic displacement of chlorine and formation of free radicals upon the reaction of glutathione with PCB quinones. Proc Natl Acad Sci USA 106:9725-9730.

3. Zhu BZ, Shan GQ (2009) Potential mechanism for pentachlorophenol-induced carcinogenicity: A novel mechanism for metal-independent production of hydroxyl radicals. Chem Res Toxicol 22:969-977.

4. Meunier B (2002) Catalytic degradation of chlorinated phenols. Science 296:270-271.

5. Gupta SS, et al. (2002) Rapid total destruction of chlorophenols by activated hydrogen peroxide. Science 296:326-328.

6. Sorokin A, Seris JL, Meunier B (1995) Efficient oxidative dechlorination and aromati ring-cleavage of chlorinated phenols catalyzed by iron sulfophthalocyanine. Science 268:1163-1166.

7. Zhao YL, Qin F, Boyd JM, Anichina J, Li XF (2010) Characterization and determination of chloro- and bromo-benzoquinones as new chlorination disinfection byproducts in drinking water. Anal Chem 82:4599-4605.

8. Halliwell B, Gutteridge JMC (2007) Free Radicals in Biology and Medicine (Oxford University Press, Oxford) p 45.

9. Wagner JR, Cadet J (2010) Oxidation reactions of cytosine DNA components by hydroxyl radical and one-electron oxidants in aerated aqueous solutions. Acc Chem Res 43:564-571.

10. Xu G, Chance MR (2007) Hydroxyl radical-mediated modification of proteins as probes for structural proteomics. Chem Rev 107:3514-3543.

11. Voinov MA, Pagan JOS, Morrison E, Smirnova TI, Smirnov Al (2011) Surface-mediated production of hydroxyl radicals as a mechanism of iron oxide nanoparticle biotoxicity. J Am Chem Soc 133:35-41.

12. Montzka SA, et al. (2011) Small interannual variability of global atmospheric hydroxyl. Science 331:67-69.

13. Rohrer F, Berresheim H (2006) Strong correlation between levels of tropospheric hydroxyl radicals and solar ultraviolet radiation. Nature 442:184-187.

14. Zhu BZ, Zhao HT, Kalyanaraman B, Frei B (2002) Metal-independent production of hydroxyl radicals by halogenated quinones and hydrogen peroxide: An ESR spin trapping study. Free Radical Biol Med 32:465-473.

15. Zhu BZ, Kalyanaraman B, Jiang GB (2007) Molecular mechanism for metalindependent production of hydroxyl radicals by hydrogen peroxide and halogenated quinones. Proc Natl Acad Sci USA 104:17575-17578.

16. Zhu BZ, et al. (2007) Mechanism of metal-independent decomposition of organic hydroperoxides and formation of alkoxyl radicals by halogenated quinones. Proc Nat Acad Sci USA 104:3698-3702. cuvette and the photomultiplier tube. During the determination of $\mathrm{CL}$ wavelength, appropriate corrections were applied for both spectral response of the photomultiplier tube and transmissivity of filters.

The Kinetic Study of ${ }^{-0 H}$ Formation by Both ESR and Fluorescent Methods. The time courses for $\bullet \mathrm{OH}$ formation by $\mathrm{TCBQ} / \mathrm{H}_{2} \mathrm{O}_{2}$ and $\mathrm{TrCBQ}-\mathrm{OH} / \mathrm{H}_{2} \mathrm{O}_{2}$ were monitored by both ESR with DMPO as the spin-trapping agent, and by fluorescence with 3-CCA as an ${ }^{\bullet} \mathrm{OH}$ probe. The basic system consisted of $0.1 \mathrm{mM}$

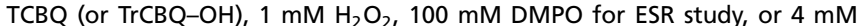
3-CCA for fluorescent study, in $0.1 \mathrm{M}$ Chelex-treated phosphate buffer ( $\mathrm{pH}$ 7.4) at room temperature. ESR spectra were recorded either immediately after the interaction of TCBQ (or TrCBQ-OH) with $\mathrm{H}_{2} \mathrm{O}_{2}$, or at indicated time intervals on a Bruker ER 200 D-SRC spectrometer operating at $9.8 \mathrm{GHz}$. Fluorescence detection was preformed on a Cary Eclipse (Varian) spectrofluorometer. Samples with $3-\mathrm{CCA}$ as the $\cdot \mathrm{OH}$ probe were excited at $388 \mathrm{~nm}$, and the resulting fluorescence was measured at $446 \mathrm{~nm}$.

ACKNOWLEDGMENTS. The authors acknowledge the technical help provided by Drs. Jin-Ming Lin, Li-Xia Zhao, and Frederick Villamena. This work was supported by Project 973 (2008CB418106); Hundred-Talent Project, Chinese Academy of Sciences; National Science Foundation China Outstanding Youth Award (20925724); National Science Foundation China Grants 20877081, 20890112, 20921063, 21207139, and 21237005; and National Institutes of Health Grants ES11497, RR01008, and ES00210.

17. Zhu BZ, Shan GQ, Huang CH, Kalyanaraman B, Mao L, Du YG (2009) Metalindependent decomposition of hydroperoxides by halogenated quinones: Detection and identification of a quinone ketoxy radical. Proc Natl Acad Sci USA 106:11466-11471.

18. Zhu BZ, Zhu JG, Mao L, Kalyanaraman B, Shan GQ (2010) Detoxifying carcinogenic polyhalogenated quinones by hydroxamic acids via an unusual double Lossen rearrangement mechanism. Proc Natl Acad Sci USA 107:20686-20690.

19. Kanakubo A, Isobe $M(2005)$ Isolation of brominated quinones showing chemiluminescence activity from luminous acorn worm, Ptychodera flava. Bioorg Med Chem 13:2741-2747.

20. Stevani CV, Silva SM, Badder WJ (2000) Studies on the mechanism of the excitation step in peroxyoxalate chemiluminescence. Eur J Org Chem 24:4037-4046.

21. Schuster GB (1979) Chemiluminescence of organic peroxides. Conversion of groundstate reactants to excited-state products by the chemically initiated electron-exchange luminescence mechanism. Acc Chem Res 12:366-373.

22. Matsumoto M (2004) Advanced chemistry of dioxetane-based chemiluminescent substrates originating from bioluminescence. J Photochem Photobiol C 5:27-53.

23. Adam W, Kazakov DV, Kazakov VP (2005) Singlet-oxygen chemiluminescence in peroxide reactions. Chem Rev 105:3371-3387.

24. Bos R, et al. (2009) In search of a chemiluminescence 1,4-dioxy biradical. J Am Chem Soc 131:2770-2771.

25. Saleh L, Plieth C (2010) Total low-molecular-weight antioxidants as a summary parameter, quantified in biological samples by a chemiluminescence inhibition assay. Nat Protoc 5:1627-1634.

26. Widder EA (2010) Bioluminescence in the ocean: Origins of biological, chemical, and ecological diversity. Science 328:704-708.

27. Chignell CF, et al. (2008) EPR studies of in vivo radical production by $3,3^{\prime}, 5,5^{\prime}$-tetrabromobisphenol A (TBBPA) in the Sprague-Dawley rat. Toxicol Appl Pharmacol 230:17-22.

28. Teuten EL, Us L, Reddy CM (2005) Two abundant bioaccumulated halogenated compounds are natural products. Science 307:917-920.

29. Kelly BC, Ikonomou MG, Blair JD, Morin AE, Gobas FAPC (2007) Food web-specific biomagnification of persistent organic pollutants. Science 317:236-239.

30. Pera-Titus M, García-Molina V, Baños MA, Giménez J, Esplugas S (2004) Degradation of chlorophenols by means of advanced oxidation processes: A general review. App/ Catal B 47:219-256.

31. Zimbron JA, Reardon KF (2009) Fenton's oxidation of pentachlorophenol. Water Res 43:1831-1840. 